\title{
Propriedades físico-químicas de frutos de jurubeba de três regiões do Cerrado
}

\author{
Luiz Fernandes Cardoso Campos ${ }^{1}$, Joicy Vitória Miranda Peixoto ${ }^{1}$, Renata Maria de \\ Oliveira $^{1}$, Alexsander Seleguini ${ }^{1}$, Abadia dos Reis Nascimento ${ }^{1}$ \\ ${ }^{1}$ Universidade Federal de Goiás, Goiânia, Goiás, Brasil. E-mail: luizfernandescampos@ hotmail.com, \\ joicyvmpeixoto@yahoo.com.br, renata_oliveira89@hotmail.com, aseleguini@gmail.com, reyzynha@yahoo.com.br
}

Recebido: 06/10/2015; Aceito: 15/12/2015.

\section{RESUMO}

A jurubeba é uma espécie solanácea amplamente difundida em toda a América Tropical, sendo nativa nas Regiões Norte e Nordeste do Brasil. Os seus frutos são utilizados na culinária, na medicina popular para o tratamento de fígado e disfunções gástricas. A planta apresenta potencial de controle biológico contra fitopatógenos e pragas de relevância agronômica. Diante dos seus benefícios e devido à escassez de estudos relacionado a esta, objetivou-se com este trabalho caracterizar os parâmetros físicos e químicos de frutos de jurubeba, colhidos em diferentes regiões do Cerrado; em Goiânia, Itapuranga no Estado de Goiás e Araguari em Minas Gerais. Analisou-se a massa, diâmetro longitudinal (DL), diâmetro transversal (DT), relação DL/DT, pH, sólidos solúveis, acidez titulável e número de sementes por fruto. Para as sementes foi determinado a massa de mil sementes e o teor de umidade. A caracterização dos frutos de jurubeba permitiu concluir que estes apresentam formato globoso, com número médio de sementes entre 140 a 403 e massa média de 0,67 a 1,87 g. Existe correlação entre o número de sementes por fruto e o seu tamanho. Os frutos de jurubeba são de baixa acidez e elevado teor de sólidos solúveis.

Palavras-chave: Solanum paniculatum L., frutos tropicais, despolpamento.

\section{Physical and chemical characterization of jurubeba fruit three Brazil regions}

\section{ABSTRACT}

Jurubeba is a solanaceae species widespread throughout tropical America, being native from the North and Northeast regions of Brazil. Its fruits are used in cooking, in folk medicine for the treatment of liver and gastric disorders. The plant has the potential of biocontrol against plant pathogens and pests of agronomic importance. Before their benefits and importance and because of the scarcity of studies related to this specie, the aim of this study was to characterize the physical and chemical parameters of jurubeba fruit, collected from the different Cerrado regions (Goiânia and Itapuranga in the Goiás State and Araguari in the Minas Gerais State). The fruit mass, longitudinal diameter (LD), transverse diameter (TD), DL/TD, $\mathrm{pH}$, soluble solids, titratable acidity and number of seeds per fruit were measured. In the seeds were determined the thousand seed mass and moisture content. The characterization of the fruits of jurubeba allowed the conclusion that they present a round shape, with an average number of seeds between 140-403 and average fruit mass from 0.67 to $1.87 \mathrm{~g}$. There is a correlation between the number of seeds per fruit and its size. The fruits of jurubeba are low acidity high content of soluble solids.

Key words: Solanum paniculatum L., tropical fruit, pulping. 


\section{Introdução}

A solanácea Solanum paniculatum L., conhecida popularmente como jurubeba, é uma planta considerada invasora, nativa do Brasil, de ocorrência em outras regiões tropicais da América do Sul como Paraguai, Bolívia e Argentina. Da planta de jurubeba aproveita-se raiz, caule, folhas, flores e frutos, sendo esta amplamente utilizada para fins medicinais e na culinária (GARCIA et al., 2008; VIEIRA JÚNIOR et al., 2015).

A planta é rústica, sendo resistente à seca, não possui exigência quanto à fertilidade adaptando-se a diferentes tipos de solo. Seus frutos são importantes na economia, pois são comercializados em indústrias de bebidas, sendo essenciais na produção do vinho da jurubeba (SANTOS, 2013).

Os frutos da jurubeba são pequenas esferas verdes, ou esbranquiçadas quando maduras, crescem em forma de cacho e apresentam sabor amargo. A colheita é iniciada aos seis meses após o plantio, podendo ser estendida por seis meses. Os cachos com os frutos são colhidos ainda verdes em razão de as sementes de frutos maduros serem muito duras e fibrosas. Estes frutos são usados na alimentação humana, principalmente em Goiás e Minas Gerais, na região do Triângulo Mineiro (BRASIL, 2015).

Ainda nos frutos, são encontrados compostos ativos e metabólitos secundários, como esteroides, saponinas, alcaloides e glicosídeos, de importância farmacológica, sendo utilizados na medicina popular brasileira para o tratamento de disfunções gástricas, hepatite, prevenção de tumores uterinos, como descongestionante e antitérmico (MESIA VELA et al., 2002; AGRA et al., 2007; MIRANDA et al., 2013). Para fins culinários o fruto é utilizado como tempero, em conservas e aditivo em aguardente de cana, em várias regiões do Brasil (LORENZI; MATOS, 2002).

Estudos recentes apontam a jurubeba como uma espécie com potencial para o controle de fitopatógenos. Há relatos que na Amazônia, em pequenas culturas, a enxertia de tomateiro em jurubeba é uma prática utilizada para o controle de murcha-bacteriana, causada por Ralstonia solanacearum (SANTOS; GOTO, 2004).

$\mathrm{O}$ porta-enxerto resistente à murcha bacteriana na cultura do tomate pode ser oriundo de tomateiro ou genótipos de outras solanáceas pertencentes a espécies ou gêneros distintos, como as diferentes espécies de jurubeba que pertencem ao gênero Solanum e subgênero Leptostemonum, o jiló, a berinjela dentre outros (GOTO et al., 2003). A utilização do tomateiro como portaenxerto possui a vantagem de facilitar a produção de mudas com alta taxa de pegamento da enxertia. No entanto, há a desvantagem do nível de resistência do porta-enxerto não ser completa. Em contrapartida, a enxertia do tomateiro sobre outra espécie de solanácea como a jurubeba, garante melhor nível de proteção à planta (LOPES, 2009).

Considerando-se a escassez de pesquisas com $S$. paniculatum L., sua importância medicinal, alimentícia e agronômica objetivou-se caracterizar os parâmetros físicos e químicos de frutos de jurubeba, colhidos em diferentes regiões do Cerrado.

\section{Material e Métodos}

Frutos de jurubeba foram coletados, nos municípios de Goiânia, Goiás, (16 $41^{\circ}$ latitude sul, 49 $19^{\circ}$ ' longitude oeste e altitude média de $730 \mathrm{~m}$ ); Itapuranga, Goiás, provenientes de plantas localizadas na fazenda Capoeira Grande ( $15^{\circ} 34^{\prime}$ Latitude Sul, $50^{\circ}$ 00' Longitude Oeste e altitude média de $635 \mathrm{~m}$ ); e Araguari, Minas Gerais (18 $38^{\prime}$ ' Latitude Sul, 48 ${ }^{\circ} 11^{\prime}$ longitude oeste e altitude média de $940 \mathrm{~m}$ ).

Os frutos coletados em Araguari-MG e ItapurangaGO encontravam-se no estádio de maturação "de vez" (sementes apresentando embrião completamente desenvolvido e de coloração creme), enquanto os frutos colhidos em Goiânia-GO estavam verdes (sementes imaturas e de coloração transparente). Os frutos estavam em perfeito estado, inteiros, sem injúrias e frescos. Para a caracterização física foram utilizados cinquenta frutos de jurubeba de cada local de coleta e procedeu-se à medição do diâmetro longitudinal e transversal com o auxílio de paquímetro digital.

De posse desses resultados foi calculada a relação diâmetro longitudinal/transversal que fornece a informação de formato do fruto. A massa desses frutos foi mensurada em balança analítica digital. Para a contagem do número de sementes por fruto, foram utilizados vinte frutos aleatoriamente de cada local de coleta. Determinou-se também a massa de mil sementes de oito subamostras de 100 sementes, que foram contadas e em seguida pesadas em balança analítica com precisão de 0,001g. A determinação do teor de umidade foi realizada segundo a AOAC (2010).

Para a caracterização química de $S$. paniculatum, dez frutos de cada local foram macerados em almofariz, extraindo-se o suco para as determinações analíticas, em triplicata, do teor de sólidos solúveis (SS), potencial hidrogeniônico $(\mathrm{pH})$ e acidez total titulável (ATT). O SS ( ${ }^{\circ}$ Brix) foi determinado em refratômetro manual, o $\mathrm{pH}$ em medidor de $\mathrm{pH}$ de bancada, calibrado com soluções tampão pH 4,0 e pH 7,0, e ATT por meio de titulação, conforme normas analíticas do AOAC (2010).

Os resultados das análises físicas e químicas foram submetidos à análise de estatística descritiva. Foi estimado o coeficiente de correlação de Pearson a 5\% de probabilidade pelo teste $\mathrm{t}$ de Student, para a associação entre as características físicas dos frutos, 
utilizando o software Assistat versão 7.7 beta (SILVA; AZEVEDO, 2002).

\section{Resultados e Discussão}

De maneira geral, independentemente dos locais de coleta, os frutos de jurubeba apresentaram menores diâmetros longitudinais (média de $12,11 \mathrm{~mm}$ ), do que transversais (média de 12,68 mm). Moraes et al. (2009) descrevem as dimensões do fruto em $6-11 \mathrm{~mm}$ de diâmetro longitudinal e 8 - $18 \mathrm{~mm}$ de diâmetro transversal, enquanto Agra et al. (2009) descrevem o fruto com $15 \mathrm{~mm}-17 \mathrm{~mm}$ de diâmetro transversal. Athiê e Dias (2012) observaram frutos de comprimento médio de $14 \mathrm{~mm}$ e diâmetro médio de $13 \mathrm{~mm}$. Marques et al. (2012) encontraram frutos da espécie $S$. paniculatum variando entre 10 a $12 \mathrm{~mm}$ de diâmetro transversal. Essa variação no tamanho do fruto é comum nos frutos do cerrado como a jurubeba, tendo em vista que são espécies ainda não domesticadas (SILVA et al., 2012).

A relação diâmetro longitudinal/diâmetro transversal (DL/DT), em média, foi próxima a 1. Observou-se nesta relação valores de $0,97 \mathrm{~mm}, 0,94 \mathrm{~mm}$ e $0,95 \mathrm{~mm}$ para os frutos coletados em Araguari, Itapuranga e Goiânia respectivamente (Tabela 1). Isso indica que o fruto apesar de globoso (MORAES et al.,2009; AGRA et al., 2009) é levemente achatado nos polos.
Os frutos coletados em Araguari apresentaram o número médio de sementes por fruto de 201,7 $\pm 35,22$ e valor mínimo de 140 e máximo de 260 sementes por fruto. Já nos frutos coletados em Itapuranga foi observado $351,05 \pm 28,97$ sementes por fruto, sendo o valor mínimo de 292 e máximo de 394 sementes. Nos frutos coletados em Goiânia verificou-se 322,8 \pm 42,37 e os valores mínimo 223 e máximo 403 sementes por fruto (Tabela 1). De acordo com Taiz e Zeiger (2011) a quantidade de sementes presente em frutos está diretamente relacionada à polinização, além de fatores ambientais e fisiológicos. As abelhas da família Halictidae são os principais agentes polinizadores da cultura da jurubeba (MAIA-SILVA et al., 2012). A polinização incrementa a massa de frutos e garante elevado número de sementes (NUNES-SILVA et al., 2013). O desenvolvimento do fruto varia de acordo com a produção de auxinas, a qual é dependente da quantidade de sementes (HIGUTI et al., 2010).

Athiê e Dias (2012) quantificaram 132,1 sementes por fruto de jurubeba. Este valor está abaixo dos obtidos neste trabalho. Rodrigues et al. (2014) observaram em physalis uma correlação significativa de 0,972 entre massa de sementes e número de sementes. Para massa do fruto e número de sementes eles notificaram correlação negativa e significativa de $-0,310$ o que demonstra que quanto maior a quantidade de sementes no fruto, menor será a quantidade de polpa.

Tabela 1. Valores médios dos parâmetros físicos de frutos de jurubeba (Solanum paniculatum L.) coletados em três diferentes regiões do cerrado brasileiro.

\begin{tabular}{|c|c|c|c|c|c|}
\hline Parâmetros & $X^{1} \pm S^{2}$ & Variância & $\mathrm{CV}(\%)^{3}$ & Mínimo & Máximo \\
\hline & \multicolumn{5}{|c|}{ Araguari (MG) } \\
\hline Diâmetro longitudinal (DL) (mm) & $11,44 \pm 0,66$ & 0,43 & 5,75 & 10,02 & 13,58 \\
\hline Diâmetro transversal (DT) (mm) & $11,74 \pm 0,69$ & 0,48 & 5,89 & 10,34 & 13,19 \\
\hline Relação DL/DT & $0,97 \pm 0,03$ & 0,001 & 3,30 & 0,90 & 1,05 \\
\hline Número de sementes/fruto & $201,70 \pm 35,22$ & 1240,85 & 17,46 & 140,00 & 260,00 \\
\hline \multirow[t]{2}{*}{ Massa do fruto $(\mathrm{g})$} & $1,05 \pm 0,23$ & 0,05 & 21,95 & 0,67 & 1,87 \\
\hline & \multicolumn{5}{|c|}{ Itapuranga (GO) } \\
\hline Diâmetro longitudinal (DL) (mm) & $12,45 \pm 0,39$ & 0,15 & 3,13 & 11,76 & 13,41 \\
\hline Diâmetro transversal (DT) (mm) & $13,21 \pm 0,39$ & 0,16 & 3,02 & 12,39 & 14,17 \\
\hline Relação DL/DT & $0,94 \pm 0,02$ & 0,0003 & 1,99 & 0,91 & 0,99 \\
\hline Número de sementes/fruto & $351,05 \pm 28,97$ & 839,52 & 8,25 & 292 & 394 \\
\hline \multirow[t]{2}{*}{ Massa do fruto $(\mathrm{g})$} & $1,38 \pm 0,13$ & 0,02 & 9,14 & 1,17 & 1,69 \\
\hline & \multicolumn{5}{|c|}{ Goiânia (GO) } \\
\hline Diâmetro longitudinal (DL) (mm) & $12,43 \pm 0,47$ & 0,22 & 3,75 & 11,49 & 13,64 \\
\hline Diâmetro transversal (DT) (mm) & $13,08 \pm 0,51$ & 0,26 & 3,93 & 11,63 & 14,09 \\
\hline Relação DL/DT & $0,95 \pm 0,02$ & 0,0003 & 1,98 & 0,92 & 0,99 \\
\hline Número de sementes/fruto & $322,80 \pm 42,37$ & 1794,90 & 13,12 & 223,00 & 403,00 \\
\hline Massa do fruto $(\mathrm{g})$ & $1,37 \pm 0,15$ & 0,02 & 10,74 & 1,05 & 1,73 \\
\hline
\end{tabular}

${ }^{\mathrm{T}} \mathrm{X}=$ média; ${ }^{2} \mathrm{~S}=$ desvio padrão; ${ }^{3} \mathrm{CV}(\%)=$ coeficiente de variação. ${ }^{\mathrm{T}} \mathrm{X}=$ average; ${ }^{2} \mathrm{~S}=$ standard deviation $(\mathrm{cm}) ;{ }^{3} \mathrm{CV}(\%)=$ coefficient of variation 
A massa média (em gramas de fruto fresco) dos frutos coletados em Araguari foi de 1,05 $\mathrm{g}$ com os valores mínimo e máximo de 0,67 g e $1,87 \mathrm{~g}$ respectivamente. Os frutos colhidos em Itapuranga tiveram em média $1,38 \mathrm{~g}$, sendo o valor mínimo $1,17 \mathrm{~g}$ e máximo 1,69 g. Frutos de Goiânia pesaram em média 1,37 g com mínimo e máximo de 1,05 g e 1,73 g respectivamente (Tabela 1 ). Em estudos com a espécie de jurubeba (Solanum granuloso leprosum Dunal) Athiê e Dias (2012) verificaram frutos com massa média de 1,5 g. Essa variação é atribuída ao fato de a cultura da jurubeba não ser domesticada, podendo existir variações no conteúdo químico e nutricional de seu fruto (MORZELLE et al., 2015).

Os coeficientes de variação do diâmetro longitudinal $(5,75 \%, 3,13 \%$ e $3,75 \%)$ e diâmetro transversal $(5,89 \%$, $3,02 \%$ e $3,93 \%$ ), bem como os da relação DL/DT $(3,30 \%, 1,99 \%$ e $1,98 \%), \mathrm{pH}(1,22 \%, 1,00 \%$ e $1,11 \%)$ e sólidos solúveis totais $(4,05 \%, 5,54 \%$ e 7,84\%) dos frutos coletados em Araguari, Itapuranga e Goiânia, respectivamente, apresentaram distribuição homogênea. Para as características de número de sementes por fruto (NSF) e massa do fruto (MF) o coeficiente de variação observado foi de $8,25 \%, 13,12 \%$ e $17,46 \%$ para NSF, enquanto para MF a variação foi de $9,14 \%, 10,74 \%$ e 21,95\% em Araguari, Itapuranga e Goiânia respectivamente, apresentando também distribuição homogênea (Tabela 1).

Observou-se correlação significativa, entre as diferentes características físicas avaliadas, para cada local de coleta dos frutos de jurubeba. Os frutos de Araguari apresentaram alta correlação positiva entre as variáveis, diâmetro longitudinal e transversal $(0,83)$; a variável número de semente por fruto correlacionou-se positivamente com a massa de frutos $(0,46)$ e relação DL/DT (0,48), sendo os coeficientes de ambas considerados médios (Tabela 2).

Entre as características dos frutos colhidos em Itapuranga houve correlação significativa apenas para as variáveis, diâmetro transversal e diâmetro longitudinal, com coeficiente de 0,86 , sendo este considerado alto. A mesma correlação ocorreu para os frutos de Goiânia, e com mesmo coeficiente $(\mathrm{r}=0,86)$; também houve correlação entre número de sementes por fruto e relação DL/DT, sendo esta uma correlação negativa $(r=-0,53)$ (Tabela 2).

A correlação altamente positiva entre os diâmetros transversal e longitudinal, dos frutos de jurubeba provenientes dos três locais de coleta, confirma que o formato dos frutos é globoso (Tabela 1). A correlação entre o NSF e relação DL/DT observada em frutos de Araguari e Goiânia, indicam que a quantidade de sementes influencia o tamanho dos frutos, de modo que quanto maior foi o fruto maior é o número de sementes, desde que haja uma eficiente polinização. Neste estudo acredita-se que a polinização das flores foi eficiente, principalmente, devido ao elevado número de sementes.

Quanto as características químicas, o valor de $\mathrm{pH}$, acidez titulável (ATT) e sólidos solúveis (SS) observado nos frutos "de vez" provenientes de Araguari foi de 5,$65 ; 0,37 \%$ e $24,58^{\circ}$ Brix respectivamente. Já nos frutos "de vez" advindos de Itapuranga verificou-se $\mathrm{pH}$ de 5,$77 ; 0,20 \%$ de acidez titulável e teor de SS de $18,48^{\circ}$ Brix. Nos frutos verdes colhidos em Goiânia o pH observado foi de 5,75, acidez titulável de 0,20\% e sólidos solúveis de $16,72^{\circ}$ Brix (Tabela 3 ).

Tabela 2 - Matriz de coeficientes de correlação linear de Pearson das variáveis: massa de frutos (MF), diâmetro longitudinal (DL), diâmetro transversal (DT), relação DL/DT e número de sementes por fruto (NSF), de frutos de jurubeba (Solanum paniculatum L.) coletados em três diferentes regiões do Cerrado brasileiro.

\begin{tabular}{|c|c|c|c|c|c|}
\hline Variáveis & $\mathrm{MF}$ & DL & DT & DL/DT & NSF \\
\hline & \multicolumn{5}{|c|}{ Araguari (MG) } \\
\hline MF & 1 & & & & \\
\hline DL & 0,21 & 1 & & & \\
\hline DT & 0,12 & $0,83^{* *}$ & 1 & & \\
\hline DL/DT & 0,14 & 0,24 & $-0,33$ & 1 & \\
\hline \multirow[t]{2}{*}{ NSF } & $0,46^{*}$ & 0,01 & $-0,27$ & $0,48^{*}$ & 1 \\
\hline & \multicolumn{5}{|c|}{ Itapuranga (GO) } \\
\hline MF & 1 & & & & \\
\hline DL & $-0,06$ & 1 & & & \\
\hline DT & $-0,23$ & $0,86^{* *}$ & 1 & & \\
\hline DL/DT & 0,31 & 0,37 & $-0,15$ & 1 & \\
\hline \multirow[t]{2}{*}{ NSF } & $-0,09$ & $-0,33$ & $-0,21$ & $-0,27$ & 1 \\
\hline & \multicolumn{5}{|c|}{ Goiânia (GO) } \\
\hline MF & 1 & & & & \\
\hline DL & 0,16 & 1 & & & \\
\hline DT & 0,18 & $0,86^{* *}$ & 1 & & \\
\hline DL/DT & $-0,04$ & 0,19 & $-0,34$ & 1 & \\
\hline NSF & $-0,09$ & $-0,32$ & $-0,03$ & $-0,53^{*}$ & 1 \\
\hline
\end{tabular}


Valores de $\mathrm{pH}$ inferior a 4,5 inibe a proliferação de microrganismos no produto final. Valores superiores a este, implicam em maiores períodos de esterilização aumentando consequentemente o consumo de energia e o custo do processamento (SOARES; RANGEL, 2012).

O parâmetro sólidos solúveis totais (SS) caracterizase pelas substâncias dissolvidas no conteúdo celular. Entre estas se destacam as vitaminas, pectinas, fenóis, ácidos orgânicos, pigmentos e principalmente os açúcares (CHITARRA; ALVEZ, 2001). O SS aumenta em função dos diferentes estádios de maturação do fruto, sendo frutos mais maduros os que apresentam maior teor de SS (LIMA et al., 2002; OPARA et al., 2012).

No decorrer do desenvolvimento do fruto acontece a translocação de carboidrato, proveniente do processo de fotossíntese, da planta mãe em direção aos frutos. $\mathrm{O}$ amido, durante o estádio de maturação, é hidrolisado transformando-se em glicose e frutose (JACOMINO et al., 2015), ocorrendo também a hidrólise da protopectina em pectina solúvel o que incrementa a quantidade de SS (CHITARRA; CHITARRA, 2005).

$\mathrm{O}$ teor de SS encontrado neste experimento se refere a alta quantidade de compostos fenólicos apresentada nos frutos de jurubeba (LÔBO et al., 2010), bem como flavonóides, antocianinas, vitamina $\mathrm{C}$ e carotenóides, entretanto, a quantificação destes compostos não foram realizadas neste trabalho.
Siqueira et al. (2013) notificaram em $100 \mathrm{~g}$ do fruto de Solanum paniculatum L., a quantidade de $94 \pm 9 \mathrm{mg}$ do composto fenólico ácido tânico, 48,228 \pm 5,328 mg de flavonóides, 4,653 \pm 0,105 $\mathrm{mg}$ de antocianina, 12,95 $\pm 3,24 \mathrm{mg}$ de vitamina $\mathrm{C}$ e 1,362 $\pm 0,153 \mathrm{mg}$ de carotenóides. As diferenças observadas na composição química dos frutos podem estar relacionadas entre outras características, com as condições edafoclimáticas de cada local de plantio, genótipos e estádio de maturação (ALEXANDRE et al., 2014).

A massa de mil sementes foi maior nos frutos coletados em Araguari-MG seguido dos frutos de Itapuranga-GO (Figura 1), isto pode ser atribuído aos diferentes graus de maturação dos frutos. De acordo com Brasil (2009) a massa de mil sementes, correlaciona-se positivamente com o tamanho das sementes e com seu estado de maturação e sanidade. Verificou-se que os frutos, "de vez" apresentaram sementes completamente desenvolvidas e em grau de maturação mais avançado, constatado pela coloração bege, caraterística da semente, como descrito por Agra et al. (2009) e Moraes et al. (2009). As sementes dos frutos verdes colhidos em Goiânia estavam imaturas e apresentaram coloração branca com certa transparência. A maturação do fruto e consequente formação da semente resulta em maior acúmulo de massa seca, aumentando a massade mil sementes.

Tabela 3. Valores médios dos parâmetros químicos de frutos de jurubeba (Solanum paniculatum L.) coletados em três diferentes regiões do cerrado brasileiro.

\begin{tabular}{lccccc}
\hline \multicolumn{1}{c}{ Parâmetros } & $\mathrm{X}^{1} \pm \mathrm{S}^{2}$ & Variância & $\mathrm{CV}(\%)^{3}$ & Mínimo & Máximo \\
\hline & \multicolumn{3}{c}{ Araguari (MG) } \\
\cline { 2 - 6 } pH & $5,65 \pm 0,07$ & 0,005 & 1,22 & 5,55 & 5,70 \\
Sólidos Solúveis ( ${ }^{\circ}$ Brix) & $24,58 \pm 0,99$ & 0,99 & 4,05 & 23,00 & 25,60 \\
Acidez Titulável (\%) & $0,37 \pm 0,05$ & 0,002 & 13,33 & 0,30 & 0,40 \\
\hline & & Itapuranga (GO) & 5,83 \\
pH & $5,77 \pm 0,06$ & 0,003 & 1,00 & 5,72 & 20,40 \\
Sólidos Solúveis ( ${ }^{\circ}$ Brix) & $18,48 \pm 1,02$ & 1,05 & 5,54 & 17,00 & 0,23 \\
Acidez Titulável (\%) & $0,20 \pm 0,02$ & 0,0006 & 12,25 & 0,17 & \\
\hline & & & Goiânia (GO) & \\
pH & & 0,004 & 1,11 & 5,70 & 5,84 \\
Sólidos Solúveis ( ${ }^{\circ}$ Brix) & $5,75 \pm 0,06$ & 1,72 & 7,84 & 14,20 & 18,40 \\
Acidez Titulável (\%) & $16,72 \pm 1,31$ & 0,0006 & 12,25 & 0,17 & 0,20
\end{tabular}

${ }^{1} \mathrm{X}=$ média; ${ }^{2} \mathrm{~S}=$ desvio padrão $(\mathrm{cm}) ;{ }^{3} \mathrm{CV}(\%)=$ coeficiente de variação. ${ }^{1} \mathrm{X}=$ average; ${ }^{2} \mathrm{~S}=$ standard deviation $(\mathrm{cm}) ;{ }^{3} \mathrm{CV}(\%)=$ coefficient of variation. 


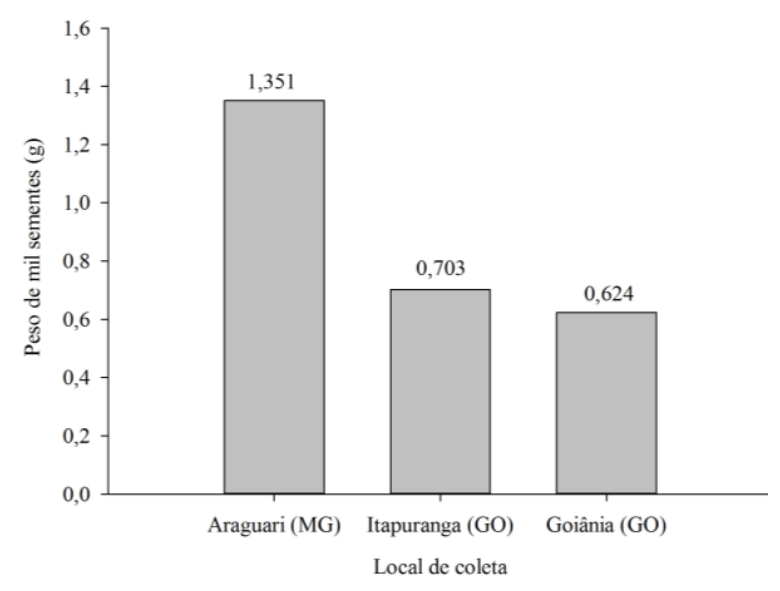

Figura 1. Massa de mil sementes de jurubeba (Solanum paniculatum L.) de frutos provenientes de diferentes regiões do Cerrado brasileiro.

Em experimento avaliando a qualidade fisiológica de sementes de pimenta Pereira et al. (2014) verificaram que a maior massa de mil sementes $(8,88 \mathrm{~g})$ foi encontrado em frutos de coloração vermelho intensa, coincidindo com o momento em que ocorreu o máximo acúmulo de matéria seca de 100 sementes.

$\mathrm{O}$ teor de umidade observado nas sementes provenientes dos frutos de Araguari foi de 8,3\%, nos frutos de Itapuranga 9,3\% e em frutos de Goiânia 9,2\%. Esperava-se maior valor para o teor de umidade nas sementes provenientes dos frutos coletados em Goiânia, pois estas encontravam-se imaturas. No entanto essa diferença pode ser atribuída às condições ambientais ou genética do material. De acordo com Welbaum e Bradford (1990) o grau de maturidade pode ser influenciado por fatores ambientais e genéticos, não sendo, portanto, um indicador seguro de maturidade fisiológica, embora seja muito utilizado.

\section{Conclusões}

Frutos de jurubeba jurubeba (Solanum paniculatum L.) possuem formato globoso, com número médio de sementes entre 140 a 403 por fruto, e massa média de 0,67 a $1,87 \mathrm{~g}$.

O estádio de maturação interfere nas propriedades químicas dos frutos de jurubeba. Os frutos possuem baixa acidez e elevado teor de sólidos solúveis.

$\mathrm{O}$ número de sementes no fruto influenciam seu tamanho. Para sementes em completa maturidade fisiológica, a massa de mil sementes varia de 0,703 a $1,351 \mathrm{~g}$.

\section{Referências Bibliográficas}

AGRA, M. F.; BARACHO, G. S.; NURIT-SILVA, K.; BASILIO, I. J. L. D; COELHO, V. P. M. Medicinal and poisonous diversity of the flora of "Cariri Paraibano", Brazil.
Journal of Ethnopharmacology. Laussane, v. 111, n. 2, p. 383-395, 2007.

AGRA, M. F.; NURIT-SILVA, K.; BERGER, L. R. Flora da Paraíba, Brasil: Solanum L. (Solanaceae). Acta Botânica Brasílica, São Paulo-SP, v. 23, n. 3, p. 826-842, 2009.

ALEXANDRE, H. V.; FIGUEIRÊDO, R. M. F.; QUEIROZ, A. J. M.; OLIVEIRA, E. N. A. Armazenamento de pitanga em pó. Comunicata Scientiae, Campina Grande-PB, v. 5, n. 1, p. 83-91, 2014.

AOAC. ASSOCIATION OF OFFICIAL ANALYTICAL CHEMISTS. Official methods of analysis of Association of Official Analytical Chemists. Gaithersburg: AOAC, 2010.

ATHIÊ, S.; DIAS, M. M. Frugivoria por aves em um mosaico de Floresta Estacional Semidecidual e reflorestamento misto em Rio Claro, São Paulo, Brasil. Acta Botânica Brasilica, São Carlos-SP, v. 26, n. 1, p. 84-93, 2012.

BRASIL. MINISTÉRIO DA AGRICULTURA, PECUÁRIA E ABASTECIMENTO. Regras para análise de sementes. Ministério da Agricultura, Pecuária e Abastecimento. Secretaria de Defesa Agropecuária, Brasília-DF: MAPA/ACS, 2009. 395p.

BRASIL. MINISTÉRIO DA SAÚDE. Secretaria de Atenção à Saúde. Departamento de Atenção Básica. Alimentos regionais brasileiros. Ministério da Saúde, Secretaria de Atenção à Saúde, Departamento de Atenção Básica. 2. ed. Brasília: Ministério da Saúde, 2015. 484 p.

CAUSSE, M.; BURET, M.; ROBINI, K.; VERSCHAVE, P. Inheritance of nutritional and sensory quality traits in fresh market tomato and relation to consumer preferences. Journal of food science, Champaign, v. 68, n. 7, p. 2342-2350, 2003.

CHITARRA, A. B.; ALVES, R. E. Tecnologia de póscolheita para frutos tropicais. Fortaleza-CE: FRUTAL SINDIFRUTA, 2001. v. 1, 314 p.

ChITARRA, M. I. F.; CHITARRA, A. B. Pós-colheita de frutas e hortaliças: fisiologia e manuseio. Lavras: FAEPE, 2005. $2^{\circ}$ ed. 783 p.

GARCIA, J.; JACOBSON, T. K. B.; FARIAS, J. G.; BOAVENTURA, R. F. Effectiveness of methods to increase the germination rate of jurubeba (Solanum paniculatum L.) seeds. Pesquisa Agropecuária Tropical, Goiânia-GO, v. 38, n. 3, p. 223-226, 2008.

GOTO R.; SANTOS H. S.; CAÑIZARES, K. A. L. Enxertia em hortaliças. Botucatu-SP: Editora UNESP. 2003. p. 86.

HIGUTI, A. R. O.; GODOY, A. R.; SALATA, A. C.; CARDOSO. A. I. I. Produção de tomate em função da "vibração" das plantas. Bragantia, Campinas-SP, v. 69, n. 1, p. 87-92, 2010.

JACOMINO, A. P.; ARRUDA, M. C.; BRON, I. U.; KLUGE, R. A. Transformações bioquímicas em produtos hortícolas após a colheita. In: KOBLITZ, M. G. B. (Ed.). Bioquímica de alimentos: Teoria e aplicações práticas. Rio de Janeiro: Guanabara Koogan, 2015, cap. 6, p. 153-189.

LIMA, E. D. P. A.; LIMA, C. A. A.; ALDRIGUE, M. L.; GONDIM, P. J. S. Caracterização química e física dos frutos 
da umbu-cajazeira (Spondias spp) em cinco estádios de maturação, da polpa congelada e néctar. Revista Brasileira de Fruticultura, Jaboticabal-SP, v. 24, n. 2, p. 338-343, 2002.

LÔBO, K. M. S.; ATHAYDE, A. C. R; SILVA, A. M. A.; RODRIGUES, F. F. G.; LÔBO, I. S.; BEZERRA, D. A. C.; COSTA, J. G. M. Avaliação da atividade antibacteriana e prospecção fitoquímica de Solanum paniculatum L am. e Operculina hamiltonii (G. Don) D. F. Austin \& Staples, do semi-árido paraibano. Revista Brasileira de Plantas Medicinais, Botucatu-SP, v. 12, n. 2, p. 227-235, 2010.

LOPES, C. A. Murcha Bacteriana ou Murchadeira - Uma Inimiga do Tomateiro em Climas Quentes. Brasília-DF: Embrapa Hortaliças, 2009. 8 p. (Comunicado Técnico, 67)

LORENZI, H.; MATOS, F. J. Plantas Medicinais no Brasil: nativas e exóticas cultivadas. São Paulo-SP: Instituto Plantarum de Estudos da Flora Ltda, 2002. 544p.

MAIA-SILVA, C.; SILVA, C. I.; HRNCIR, M.; QUEIROZ, R. T.; IMPERATRIZ-FONSECA, V. L. Guia de plantas visitadas por abelhas na Caatinga, 1 ed., Fortaleza-CE; Ed. Fundação Brasil Cidadão, 2012. 99p.

MARQUES, R. S.; JASCONE, J. R. M.; SILVA, C. E. A família solanaceae no Parque Natural Municipal da Taquara, Duque de Caxias, RJ, Brasil. Saúde \& Ambiente, Duque de Caxias-RJ, v. 7, n. 1, p. 19-23, 2012.

MESIA-VELA, S.; SANTOS, M. T.; SOUCCAR, C.; LIMALANDMAN, M. T. R.; LAPA, A. J. Solanum Paniculatum L. (Jurubeba): potente inhibitor of gastric acid secretion in mice. Phytomedicine, Munique, v. 9, n. 6, p. 508-514, 2002.

MIRANDA, M. A.; TIOSSIA, R. F. J.; SILVA, M. R., RODRIGUES, K. C.; KUEHNA, C. C.; OLIVEIRA, L. G. R. In vitro leishmanicidal and cytotoxic activities of the glycoalkaloids from Solanum lycocarpum (Solanaceae) fruits. Chemistry \& Biodiversity, Zürich, v. 10, n. 4, p. 642-648, 2013.

MORAES, A. O.; MELO, E.; AGRA, M. F.; FRANÇA, F. A família Solanaceae nos "Inselbergues" do semi-árido da Bahia, Brasil. Iheringia, Série Botânica, Porto Alegre-RS, v. 64, n. 2, p. 109-122, 2009.

MORZELLE, M. C.; BACHIEGA, P.; SOUZA, E. C.; BOAS, E. V. B. V.; LAMOUNIER, M. L. Caracterização química e física de frutos de curriola, gabiroba e murici provenientes do cerrado brasileiro. Revista Brasileira de Fruticultura, Jaboticabal-SP, v. 37, n. 1, p. 96-103, 2015.

NUNES-SILVA, P.; HNRCIR, M.; SHIPP, L.; IMPERATRIZ-FONSECA, V. L.; KEVAN, P. G. The behaviour of bombus impatiens (apidae, bombini) on tomato (lycopersicon esculentum mill., solanaceae) flowers: pollination and reward perception. Journal of Pollination Ecology, Cambridge, v. 11, n. 5, p. 33-40, 2013.
OPARA, U. L.; AL-ANI, M. R.; AL-RAHBI, N. M. Effect of fruit ripening stage on physico-chemical properties, nutritional composition and antioxidant components of tomato (Lycopersicum esculentum) cultivars. Food and Bioprocess Technology, New York, v. 5, n. 8, p. 3236-3243, 2012.

PEREIRA, F. E. C. B.; TORRES, S. B.; SILVA, M. I. L.; GRANGEIRO, L. C.; BENEDITO, C. P. Qualidade fisiológica de sementes de pimenta em função da idade e do tempo de repouso pós-colheita dos frutos. Revista Ciência Agronômica, Ceará-PE, v. 45, n. 4, p. 737-744, 2014.

SANTOS, H.S.; GOTO, R. Enxertia em plantas de pimentão no controle da murcha de fitóftora em ambiente protegido. Horticultura Brasileira, Brasília-DF, v. 22, n. 1, p. 45-49, 2004.

SANTOS, S. P. A. Jurubeba: importância e sua utilidade. Tecnologias Sociais, Recife-PE, v.1, ed. 1, 2013.

SILVA, F. H. L.; FERNANDES, J. S. C.; ESTEVES, E. A.; TITON, M.; SANTANA, R. C. Populações, matrizes e idade da planta na expressão de variáveis físicas em frutos do pequizeiro. Revista Brasileira de Fruticultura, JaboticabalSP, v. 34, n. 3, p. 806-813, 2012.

SILVA, F. A. S.; AZEVEDO, C. A. V. Versão do programa computacional Assistat para o sistema operacional Windows. Revista Brasileira de Produtos Agroindustriais, Campina Grande, v. 4, n. 1, p. 71-78,2002.

RODRIGUES, F. A.; PENONI, E. S.; SOARES, J. D. R.; SILVA, R. A. L.; PASQUAL, M. Caracterização física, química e físico-química de physalis cultivada em casa de vegetação. Ciência Rural, Santa-Maria-RS, v. 44, n. 8, p. 1411-1414, 2014.

SIQUEIRA, E. M. A.; ROSA, F. R.; FUSTINONI, A. M.; SANT'NA, P.; ARRUDA, S. F. Brazilian savanna fruits contain higher bioactive compounds content and higher antioxidant activity relative to the conventional red delicious Apple. Public Library of Science, China, v. 8, n. 8, p. 1-7, 2013.

SOARES, B. B.; RANGEL, R. Aspectos industriais da cultura. In: CLEMENTE, F. M. V. T.; BOITEUX, L. S. (Eds.) Produção de tomate para processamento industrial. 1. ed. Brasília: Embrapa, 2012. v. 1, cap. 15, p. 331-344.

TAIZ, L.; ZEIGER, E. Fisiologia vegetal. 5. ed. Porto Alegre: Artmed, 2011. 690 p.

VIEIRA JÚNIOR, G. M.; ROCHA, C. Q.; RODRIGUES, T. S.; HIRUMA-LIMA, C. A.; VILEGAS, W. New steroidal saponins and antiulcer activity from Solanum paniculatum L. Food Chemistry, London, v. 186, n. 1, p. 160-167, 2015.

WELBAUM, G. E.; BRADFORD, K. J. Water relations of seeds development and germination in muskmelon (Cucumis melo L.). Water relations of seeds and fruit development. Plant Physiology, v. 92, n. 4, p. 406-411, 1990. 